\title{
The Influence and Transformation of Advertising Media in the Era of Mobile Network over Its Traditional Forms
}

\author{
Shu Zhou \\ Public Art Education Center of Art Institute \\ Xi'an University of Technology \\ Xi'an, China 710068
}

\author{
Jie'en Guo \\ Public Art Education Center of Art Institute \\ Xi'an University of Technology \\ Xi'an, China 710068
}

\begin{abstract}
After entering the 21st century, the era of mobile Internet began, and this technology has been applied in all walks of life. Precision marketing is the biggest change of mobile Internet advertising compared with traditional media. This article analyzes the connection of the mobile network advertising media and traditional media and expounds the advantages, implementation strategies and existing problems of the mobile network advertising media. The combination of the two to increase the intensity of the information dissemination is also considered in this article.
\end{abstract}

Keywords-mobile internet advertising; traditional media; influence and connection

\section{INTRODUCTION}

As we all know, advertising means widely publicizing, and in a broad sense is to inform the public about something. Advertising in a narrow sense means a for-profit advertisement, usually referred to as commercial advertising, or economic advertising. It is a method in which a business enterprise disseminates the information of goods or service to be sold. Commodity advertising is such economic information.

Online advertising is an information dissemination activity in which a confirmed advertiser uses online media to persuade the public to buy on a fee basis. Online advertising is a new form of advertising. It is produced with the development of science and technology, the rise of new media and the Internet. It is a newborn space for the advertising world. Among the many forms of traditional advertising media, newspapers, radio and television were recognized as the three traditional advertising media. Advertising has developed along with the creation of these traditional forms. The traditional mass communication mainly include media in the traditional sense such as newspapers, outdoor, communication, radio, television as well as the Internet other than We-media. In the traditional media era, the marketing concept is based on products, starting from the characteristics of the products, and makes one-way disseminating of product information through the mass media. Throughout the operation process, consumers have always been in a passive position. There is no interactive communication mechanism with consumers in the advertising process, so it has limitations in time and space.

The concept of so-called new media or Internet media is relative to traditional media, and it is an ever-changing concept. As long as the basic elements of media composition are different from traditional media, it can be called new media. Otherwise, it is the deformation or improvement on the original basis at most. Advertisement injecting of new media refers specifically to advertising on new media, and advertisers typically put about $20 \%$ advertisement on new media. In today's mobile Internet era, new media advertising breaks the limitations of time and space in traditional advertising. It allows advertisement to be seen everywhere, greatly increasing its popularity.

Cao Guowei, CEO of Sina.com, said: "Chinese traditional media actually started at the same time as its Internet. In the process occurred a situation where traditional media and online media were integrated from the very beginning. Sina had 100 traditional media partners ten years ago, which is unimaginable abroad. Today, we have more than 2,000 traditional media partners, which is also second to none in the world. Internet media was born when traditional media was not strong enough. Due to its superiority and technological leadership, it has become a media integration platform. In fact, this media integration platform has played a very good role in disseminating influence expanding for the newly born traditional media. This relationship is a mutual-benefit one".

Internet advertising is a high-tech advertising operation method that uses online advertising platforms to place advertisements on the Internet, that is, to publish or issue advertisements on the Internet and deliver them to Internet users through advertisement banners, text links, and multimedia methods on the website. Compared with traditional media such as newspapers, magazines, television, radio advertisements and well-received outdoor advertisements, Internet advertising has a unique advantage and is an important part of implementing media strategy of modern marketing. The Internet is a brand-new advertising medium with the fastest speed and ideal effect. It is a good way for SMEs to expand, especially for companies that have 
extensive international business. In this era of mobile Internet, the transmission of advertising information to consumers has also gained a targeting and real-time ability.

The morphological innovation of online advertising has many unique advantages over traditional media, and it also stimulates traditional media advertising to generate new ideas. Now there is a phenomenon of quoting network creativity in traditional media advertisements such as TV, and at the same time, advertisers begin to question the established standards and restrictions of the traditional media. Online advertising has also spurred marketing companies to reassess the use of traditional media. Not only does online advertising have a high response rate, but it also has relatively low cost to find target customer, and can obtain better customer information while traditional media advertising cannot perform specific market segmentation like online advertising. As a result, more and more marketing fees for specific target audiences will be transferred from traditional media to the Internet, giving traditional media advertising a sense of crisis.

\section{The PROMOTION OF TRADITIONAL ADVERTISING DRIVEN BY ONLINE ADVERTISING}

In the past, many media believe that online media will pose a serious threat to traditional media. However, contrary to the expected, a few years have passed, the network has not cut off the traditional media, and the large amount of advertising investment on the website has caused many traditional media to operate in full swing. The real online advertising campaign is an amazingly effective activity that combines new media with traditional media, so that TV still has the overwhelming attraction, newspaper ads continue to have the advantage of broad exposure, and beautiful product images can be printed in magazines. In turn, a new interactive relationship among media is established by use of Internet media, bringing a win-win situation to the media of both forms as well as the advertisers.

Huang Bin, editor-in-chief of the Yangcheng Evening News Group, said: "The impact of new media on traditional media is an adaptive shock, instead of a displacement shock. The revolutionary significance of new technologies to traditional media is that it provides the audience with a platform for expression, participation, and for communication. It can be seen that the development trend of online advertising today is the mass communication. In today's market segmentation, advertising communication is also increasingly emphasizing "target audience" and "precision strike". Through certain market segmentation, online advertising, based on the specific target market of the product, can be delivered according to the characteristics of the audience.

Nowadays, with the rapid development of mobile networks, digital media TV is different from previous TV commercials in that most of the current advertisements invite some celebrity stars and cooperate with various shows, TV series and movies. It is brought into public eyes in a naturally embedding manner. The audience's requirements for advertising are getting higher and higher. They can also take the initiative to choose something that they are interested in, whether it is the product itself or the spokesperson. And nowadays, most of the advertisements are brightly colored in means of artistic expressions and adopt some technique of expression and interaction settings that are more acceptable and conform to products characteristics. So it is more likely to produce some excellent advertising works. There are also some creative advertisements that are widely circulated on video websites. Their appearance has provided better opportunities for the development of advertisements.

Online advertising can track and study user preferences, which is the advantage of the Internet compared with traditional media marketing and the basis of its precise marketing. This is almost a natural advantage of the Internet. Compared with traditional media, the on-line behavior, browsing habits, and registered personal information of netizens behind each IP can be acquired and explored through technical means. Through long-term accumulation and in-depth analysis of the above content, advertisers have the opportunity to learn more about user behaviors and preferences, and to select the best matching advertising information according to each user's behavior characteristics, location, hobbies, and so on. When a travel buff and a car enthusiast visit a page on the same website, the advertisements they see are different, because the system has recorded their behaviors and preferences, making the advertisement settings no longer the same. According to the survey results, it is possible to classify audiences into different types for different age groups, different academic qualifications, different personalities, and different degrees of attention on mobile phones and computers in mobile media which enjoy the most attention in mobile media. Based on the data, advertisers can do some research on the platform where the advertisements are posted. For example, young women have higher ratings for computers, so some makeup, skin care, beauty, etc. can be released on some platforms on the PC side. This can help to maintain the audience ratings of the ads to a greater extent and get more revenue. Of course, achieving this precision requires a variety of technical support.

Today, mobile phones have become the main means of communication for new media. Mobile media is by far the most popular, fast, convenient and mandatory platform for all media formats. Mobile advertising can be seen everywhere, from the web pages we visit, to the beginning of a video, or the advertising of the live platform. Basically, you can see hundreds of advertisements every day when you are swiping the screen, as a phubber, or when you look at the led screen that can be seen everywhere on the road. These are all ways to promote mobile advertising. In our lives, mobile advertising has taken a prominent role. The development of mobile advertising can be described as swift and violent. We have our life penetrated by it and gradually get used to and accept it. Being convenient and fast, free from space and time constraints, it is highly endorsed and loved by advertising developers. It is also an important development achievement in the information age.

However, both traditional media and online media advertisements have their own advantages and disadvantages. 
So the development of online advertising should rely on the traditional media brand to establish an interactive cooperation with traditional media; as for traditional media, it should make full use of the advantages of the network to achieve a win-win situation between online media and traditional media advertising.

Compared with traditional advertisements, although new media advertisements are more convenient and more expensive than TV advertisements, they still have some shortcomings. Because the information of the publisher on the network can be hidden, we have to have doubts about the authenticity of the advertisement on the network. The release of spam has also decreased the favorability of people about online advertising. The first thought of people on the advertisement is likely to be doubt, and then it becomes disgust. So the really useful new media advertisements are very rare. We are all afraid that phishing websites have stolen our information, and network security issues have become the focus of everyone's attention. Although the use of new media ads is beneficial, it still cannot replace traditional advertising methods in real sense. From the reality of the mobile Internet advertising industry, although the model of precision marketing has been established, the most important demand analysis and information push in marketing is still rough, and the pushed information does not meet the actual needs of users. In addition, the excavation is not deep enough. Taking Sina Weibo's advertisement push as an example, the effect of advertisement push is greatly improved compared with traditional advertisement marketing. But this improvement is actually based on the huge user base of Weibo, and the form of marketing is still a large-scale push. The true features and advantages of precision marketing are not fully utilized, which is one of the important issues that precision marketing needs to solve in the future.

The weakness of online media itself is mainly due to broadband restrictions and lack of information sources and these shortcomings can be beneficially supplemented from traditional media. On the one hand, TV media has a wellconnected cable TV network, which has the realistic possibility of building a high-speed broadband transmission network. This is the basis for the rise of a new round of Internet revolution, which will greatly increase the speed of network transmission, combining the strength of network and TV and thus creating conditions for the network to enter thousands of households.

On the other hand, traditional media has rich information resources, which can provide fresh content and materials for online media. Traditional media has a collection of information gathering networks, experienced information gathering and processing talents, and a variety of information databases. All these have great value in the "content-based" online media competition. Network media can expand the information collection channel by using the information resources of traditional media, and continuously obtain the most valuable information flow in various fields in the world.

In addition, traditional media also has strong brand resources. Some well-known news organizations have already established a good image in the hearts of a large audience. If Network media make an alliance with these organizations they can use the brand-name effects to enhance their authority and credibility. In this way can they also suppress the falseness and ineffectiveness of network information and prevent the intrusion of information waste, to attract the patronage of the majority of Internet users.

Regardless of the new model, the use of the advantages of traditional media and mobile new media to popularize itself is a necessary means. The following are advisable means:

- The first is to use the TV platform for popularization. The use of existing television resources for publicity and promotion is the most readily available, direct and effective way to attract traditional TV audience.

- The second is to use the WeChat platform for popularization. Up to the end of 2017, WeChat users have exceeded 1 billion. The promotion of WeChat platform, opening WeChat subscription and service account, and pushing promotion information, is the most effective way to attract mobile phone users.

- The third is to use the Internet platform for publicity. Using its official website or entering news clients such as Tencent, Sohu, and Netease News, it can become a sub-project, effectively increasing the number of external links, thus achieving the effect of promotion and promotion.

\section{CONCLUSION}

In short, through the above comparison, the Internet and big data technology can bring a lot of convenience to the advertising industry, and accurate marketing is an effective means to use this technology. In the era of big data, we must recognize the advantages of precision marketing and use it in the mobile Internet advertising industry to fully utilize the advantages of big data technology. However, each type of media has its own advantages and disadvantages. When advertising information needs to maximize the publicity benefit, advertisers should consider integrating traditional advertising such as traditional radio, television, newspapers and magazines with online advertising, and choose different ways according to different needs, to get the best out of your advertising.

\section{REFERENCES}

[1] Overview of Chinese traditional media advertising. 2007, 52(9): P12.

[2] Su Wei. The survival advantage of new media. 2003: 4: P69

[3] Wei Chao et al. Online advertising. Shijiazhuang: Hebei People's Publishing House, 2000: P20

[4] Qian Dandan. The advantages of online advertising and its impact on traditional advertising. Journal of Wuxi South Ocean College. 2007. (03).

[5] Sun Yanhua. Advertising: traditional media vs. online media. Youth Journalist. 2008: (11).

[6] Jin Jin. Research on the precision marketing of mobile internet advertising in the age of Big Data[J]. Modern Economic Information, 2018(01): 323-324 